who, on the basis of observations on pigs, postulated that selenium and/or vitamin $\mathrm{E}$ deficiency may cause sudden death in human infants. In addition, there is a widespread notion that breast-feeding may protect against this syndrome, ${ }^{2}$ which would be reasonable in the light of Money's hypothesis and the high concentration of vitamin $E$ in human milk (7-8 IU/1.). ${ }^{3}$ However, we have previously shown that the blood selenium levels of infants dying suddenly and in explicably are essentially identical to those of normal controls ${ }^{4}$; their plasma vitamin $\mathrm{E}$ levels appeared to be slightly lower than normal, but our initial studies were performed on only a small number of samples and thus did not permit a strong conclusion regarding this point.

We now have obtained additional data on the plasma vitamin $E$ levels of infants dying suddenly and controls. Plasma samples from 18 victims of the sudden infant death syndrome, confirmed by necropsy, were obtained through the courtesy of $\mathrm{Mr}$. Robert Creason Coroner, San Diego County. Plasma samples from 17 normal control infants were obtained from Dr. Victor H. Lipp, Department of Pediatrics, School of Medicine, University of California at San Diego. Fresh cond blood samples' from 18 normal neonates were obtained from the Blood Bank, Univer sity Hospital, San Diego. Total vitamin E levels in plasma were determined spectrophotometrically by a standard technique. ${ }^{5}$ The observed vitamin $\mathrm{E}$ levels of neonatal plasma $(0.28 \pm 0.11 \mathrm{mg} / 100 \mathrm{ml})$, while lower than those noted by Nitowsky et al., were similar to more recently published values ${ }^{8}$ the neonates had lower plasma vitamin $E$ levels than either the infants dying suddenly $(0.49 \pm 0.45 \mathrm{mg} / 100 \mathrm{ml})$ or control infants $(0.79 \pm 0.26 \mathrm{mg} / 100 \mathrm{ml}$ $\mathbf{P}=0.01$ ). The infants who died suddenly (age at death $2.33 \pm 2.85$ months), though younger than the controls $(4.28 \pm 1.97$ months), did not have significantly lower vitamin $E$ levels than the controls $(P=0.05)$. Accordingly it seems unlikely that infants dying suddenly are seriously deficient in vitamin $\mathrm{E}$ during any period of their life.

To determine the effect of breast-feeding on the incidence of the sudden infant death syndrome we have obtained dietary histories of 46 infants dying suddenly and 38 control infants in San Diego County. The two groups were similar in respect of parental social class, age, occupation, education, race, and income, date and hospital of birth, sex, race, birth order, and birth weight $(P>0.05)$ In these samples similar proportions of infants dying suddenly (39\%) and control infants $(27 \%)$ were breast-fed during early infancy $(P=0.22)$, comparable with the results of other studies. 910 While the average age at death of the 27 infants dying suddenlv who had been wholly formula-fed was $3.65 \pm$ 2.79 months, the 19 totally or partially breastfed infants died at $1.78 \pm 0.70$ months $(\mathrm{P}=0.02)$; thus breast-feeding does not appear to protect against sudden death.

All the infants who died suddenly appeared to have received an adequate amount of dietary vitamin $E$, since the infant formulas fed to them contained 4.3-7.9 IU of viramin $\mathrm{E} / 1 .^{3}$ In addition, some had received extradietary vitamin supplements containing $5 \mathrm{IU}$ of vitamin $\mathrm{E} / \mathrm{ml}$; interestingly, however, fewer infants dying suddenly than controls had received vitamin supplements
$(P=0.02)$. Though the significance of the latter observation still remains to be explained, no other differences between the dietary histories of the two groups were found. In agreement with earlier studies, ${ }^{11}$ we also noted a slightly higher incidence of maternal smoking during pregnancy in the sudden infant death group (one-tail, $\mathbf{P}=$ 0.05); other reports indicate increased mortality during the first year of life in infants whose mothers smoked during pregnancy. ${ }^{2}$ Finally, the drug intake during preg nancy of the mothers of infants dying suddenly was unremarkable, being limited to aspirin, cold remedies, and diuretics.

In summary, our studies do not support the claims that vitamin $\mathrm{E}$ and/or selenium deficiency is associated with the aetiology of sudden and unexpected death in infancy, nor that breast-feeding has any protective effect. -We are, etc.,

Department of Chemistry

W. J. RHEAD

Department of Pathology,

G. N. SchraUZER

School of Medicine.

University of California,

an Diego

Address correspondence to G.N.S. at the Department Revelle College, La Jolla, Calif, U.S.A. 92037.

1 Money, D. F. L.. New Zealand Medical fournal, 1970, 71, 32; Fournal of Pediatrics, 1970, 77,

2 Ministry of Health, Enquiry into Sudien Death in Infancy, Reports on Public Health and 1965

3 Fomon, S. J., Infant Nutrition. Philadelphia, Saunders, 1967

Rhead, W. J., Cary, E. E.. Allaway, W. H., Baltzstein, S. L., and Schrauzer, G. N., Bioinorganic Chemistry.

Bieri, J. G., Teets, L., Belavady, B., and Andrews, E. L., Proceedings of the Society for
Exterimental Biology and Medicine, 1964. 117,

6 Desai, I. D., Canatian fournal of Physiology and Pharmacology. 1968, 46.819. Pharmacology. H. Hsu, K. S... and Gordon, H. H.
Vitamins and Hormones. 1962, 20.559.

8 Lennard, P. J., Doyle, E., and Harrington, W American fournal of Clinical Nutrition, 1972 25. 480 .

Bereman, A. B., Berkwith, J. B., and Ray, C. G. Sudden Infant Death Syndrome. Seattle and Londor, University of Wurrent Problems in Pediatrics, 1973, 3. 1 .

Steele, R., and Laneworth, J. T., Canadian Me dical Association fournal, 1966, 94. 1165

2 The Health Conseavences of Smoking. A Renort of the Surgeon General. Washington. U.S. De1972 .

\section{Abortion in 1972}

SIR,-Because of my interest in and concern about abortion deaths I should like to comment on some of the statistics in the Chief Medical Officer's annual report for 1972.

(1) The risks of sepsis and haemorrhage in general are each 2.9 when pregnancy is terminated before 13 weeks, and 6.1 for sepsis and 5.1 for haemorrhage at or after 13 weeks, these being the rates per 1,000 notified abortions in each group. In other words the risks are roughly doubled after the first trimester.

(2) The report states that the pregnancy was terminated at over 13 weeks in $23 \%$ of abortions in 1971 compared with $29 \%$ in 1970. However the actual numbers of abortions performed after 13 weeks has increased from about 24,000 in 1970 to 29.000 in 1971 .

(3) Of the 7,534 hvsterotomies, 2,986 were performed before 13 weeks. It may be that this was to allow sterilization, but vaginal termination followed by laparoscopic sterilization or tubal ligation would surely be safer.

(4) A total of 6,532 vaginal terminations, either by dilatation and curettage or by vacuum aspiration, were performed at 15-23 weeks and 63 after 24 weeks. I distrust the recorded complication rates for these methods, chiefly because of the high incidence of 0-1-day stay in abortions performed in "approved places," and I personally regard vaginal termination after 15 weeks as a hazardous procedure.

(5) The sepsis rates when utus paste is used, whether before $(48.5$ per 1,000$)$ or after 13 weeks ( 32.1 per 1,000$)$, should surely condemn this method.

(6) Though there has been an increase in abortions performed on women from abroad $(50,198$ in 1972) it should be noted that just over 50,000 women resident in England and Wales had abortions in "approved places," compared with 55,828 in N.H.S. hospitals.

The annual total of abortions continues to rise, but abortions must be regarded as the least satisfactory and most dangerous method of birth control. I think it is unlikely that we shall copy the Chinese in rejecting promiscuity, but the only alternative is to persuade participants to use the more efficient methods of contraception which have been developed. Meanwhile abortions after the first trimester should be done only if there is a danger to life or a serious risk of fetal abnormality.-I am, etc.,

HUMPHREY ARTHURE

London W.1

1 Department of Health and Social Security, On he State of the Public Health, Annual Report of the Chief Medi

\section{Rubella Arthritis}

SIR,-Your leading article (27 October, p. 186) prompts me to report a possible associated complication of rubella.

After rubella a 35-year-old married woman developed polyarthritis which, within a week, responded to phenylbutazone. Ten days later she developed an extremely acute right carpal tunnel syndrome with lesser symptoms in the left hand. As she was not relieved by pethidine or by local injection of hydrocortisone, after three sleepless nights complete relief was obtained by division of the flexor retinaculum under a general anaesthetic. The flexor synovial sheath was seen to be pale yellow, glistening, and swollen. Examination of a section (Dr. R. T. Cooke) showed delicate infiltration with polymorphonuclear leucocytes. The less severe pain in the left hand persisted and was relieved recently by operation.

There were no general signs of fluid retention, so I presume that the wrist synovial swellings were part of a viral synovitis rathe than a side effect of phenylbutazone.-I am etc.,

Stockton-on-Tees

WRAY ELLIS

\section{Influence of Digitalis on Labour}

SIR,-The conclusions reached by Drs. Judith B. Weaver and J. F. Pearson (8 September, p. 519) concerning the apparent 